\title{
Aspectos geoquímicos e geofísicos em área afetada por depósito de resíduos sólidos urbanos na região de Palmas - Paraná
}

\author{
The geochemical and geophysical aspects of areas affected by the deposit of urban waste in Palmas \\ - Paraná
}

RENATA VASCONCELLOS BASSO FONSECA*, ANDRÉ V. L.BITTENCOURT **, AUGUSTINHO RIGOTI**

* renata@unics.edu.br

**UFPR - Departamento de Geologia

\begin{abstract}
Resumo
A produção de lixo doméstico como resultado das atividades diárias do homem vem sofrendo a influência direta do aumento populacional, da intensidade da industrialização e da mudança dos hábitos de consumo, muitas vezes com conseqüências danosas ao meio ambiente. No município de Palmas - PR, o lixo doméstico gerado na cidade vem sendo depositado em superfície há aproximadamente dez anos em uma área situada na micro-bacia hidrográfica do Rio Passa Três, sobre rochas efusivas ácidas da Formação Serra Geral (Mesozóico da Bacia do Paraná). Tal atividade encontra-se na iminência de ser interrompida visando-se a recuperação da área, devido a suas sérias implicações ambientais e sociais. Com o objetivo de avaliar o impacto causado sobre a qualidade das águas pela deposição de resíduos sólidos no lixão e seu entorno, realizaram-se ensaios geofísicos utilizando-se a técnica de caminhamento elétrico e monitorou-se a qualidade da água superficial em córregos próximos ao depósito de lixo e no Rio Passa Três, através da análise de variáveis físicas, químicas e bacteriológicas, abrangendo dois períodos de regime hídrico: estação seca e chuvosa. A análise dos resultados evidenciou a influência do escoamento superficial sobre a qualidade das águas superficiais. Porém, a concentração dos contaminantes fica restrita à micro-bacia que abriga o lixão, não exercendo influência significativa sobre as águas do Rio Passa Três. As seções de resistividade obtidas nos ensaios de caminhamento elétrico evidenciam zonas condutoras que devem refletir a presença de chorume proveniente do lixão, alterando a salinidade e conseqüentemente a qualidade das águas do aqüífero superficial.
\end{abstract}

Palavras-chave: Lixão, geoquímica de águas, métodos elétricos, contaminação ambiental

\begin{abstract}
Domestic waste from human daily activities has been suffering a direct influence of the increasing population, the intensity of industrialization and the change in the consumers habits, sometimes with harmful consequences for the environment. In Palmas, estate of Paraná, the domestic waste has been accumulated in an uncontrolled surface deposit for about ten years, at the Hydrographic micro-basin of the Passa Três River, on effusive acid rocks of the Serra Geral formation (Mesozoic of the Paraná basin). Such area is about to be closed for environmental recovery due to the serious social and environmental problems it has created. Aiming at evaluating the impact caused by the waste on the water quality, geophysical investigation by means of electrical profiling and nearby surface water monitoring was carried out. This was performed through analysis of physical, chemical and bacteriological variables, along two different periods, a rainy and a dry season. The influence of the superficial flow on the surface water quality where evidenced. However, the concentration of contaminants is restricted to the micro-basin which hosts the waste deposit, without a significant influence on the water of the Passa Três River. Resistivity sections evidence conductive zones which may reflect the contaminants, changing the salinity and consequently degrading the groundwater quality.
\end{abstract}

Keywords: landfill, water geochemistry, geoelectrical methods, environment contamination 


\section{Introdução}

A concentração populacional em áreas urbanas e o conseqüente aumento da produção de resíduos domésticos e industriais vêm comprometendo de forma significativa a dinâmica ambiental, uma vez que a disposição de tais resíduos se dá, na maioria das vezes de forma incorreta, causando alterações na qualidade de solos, águas superficiais e subterrâneas em áreas adjacentes a lixões e aterros controlados.

Do lixo produzido no Brasil, cerca de $13 \%$ é depositado em aterros controlados, $10 \%$ em aterros sanitários, 0,9\% é submetido a compostagem e $0,1 \%$ é incinerado. $O$ restante (76\%) é depositado a céu aberto, nos chamados "lixões", segundo dados do Programa das Nações Unidas para o Meio Ambiente - PNUMA (2002).

Neste aspecto, observa-se que a maioria dos municípios lança os resíduos em locais que não apresentam as mínimas condições técnicas ou ambientais de implantação, submetendo a população e o meio a graves riscos sanitários e à deterioração dos recursos naturais.

Um lixão é caracterizado pela simples descarga de resíduos sólidos domésticos sobre o solo, sem medidas de proteção ao meio ambiente, ou a saúde pública. É conhecido também como vazadouro ou área de disposição de resíduos sólidos a céu aberto (IPT/CEMPRE, 2000).

No município de Palmas, estado do Paraná, a disposição dos resíduos sólidos urbanos vem sendo feita de forma inadequada, nos chamados lixões a céu aberto. O lixo doméstico gerado na cidade vem sendo depositado em superfície há aproximadamente dez anos, em uma área que se situa na micro-bacia hidrográfica do rio Passa Três, sobre rochas efusivas ácidas da Formação Serra Geral. Em tal local não se observam critérios pré-estabelecidos de diferenciação dos resíduos sólidos de diversas origens e também não são adotadas medidas sanitárias adequadas de tratamento e destinação final do lixo, a fim de minimizar os impactos causados ao ambiente ou à saúde pública. É constante a presença de catadores, expostos aos riscos de contaminação e de elevado número de vetores de doenças, principalmente moscas e roedores.

Entendendo a necessidade de tratar e dar uma disposição adequada a seus rejeitos e resíduos, de forma a não poluir o ambiente e pôr em risco a saúde humana, encontra-se em fase final de construção o aterro sanitário da cidade de Palmas - PR.

Devido às sérias implicações ambientais, sociais e de saúde pública e em conformidade com a legislação vigente, faz-se necessária a recuperação da área atual de depósito de lixo de Palmas. Para o correto gerenciamento da área é de fundamental importância investigação detalhada que inclui monitoramento de águas superficiais e subterrâneas para os contaminantes prioritários e avaliação das possibilidades de transporte desses contaminantes para o entorno da área afetada.

Com base nessa investigação, por meio do presente estudo pretende-se avaliar os impactos ambientais causados sobre a qualidade das águas da área de depósito de lixo da cidade de Palmas - PR e seu entorno, a fim de subsidiar as futuras ações de gerenciamento para recuperação da qualidade ambiental da referida área.

\section{Caracterização da área de estudo}

A área onde o presente estudo foi conduzido situa-se na micro-bacia hidrográfica do rio Passa Três, bacia do rio Chopim, importante afluente da margem esquerda do rio Iguaçu. O rio Passa Três tem suas nascentes próximas ao divisor de águas Iguaçu-Uruguai, no limite entre os Estados do Paraná e Santa Catarina. Após percorrer aproximadamente $10 \mathrm{Km}$ de extensão em direção Norte, as águas do rio Passa Três deságuam no rio Lontras, afluente da margem esquerda do rio Chopim.

A área objeto de estudo, conhecida como "Lixão de Palmas", possui $27.126 \mathrm{~m}^{2}$, fazendo parte de uma área maior com $481.934 \mathrm{~m} 2$ do Quinhão № 5 da Fazenda Cruzeiro, de propriedade da Companhia Agropecuária de Fomento Econômico do Paraná - Café do Paraná, cedida em comodato à Prefeitura Municipal de Palmas. Localiza-se a aproximadamente $10 \mathrm{Km}$ do centro do município de Palmas, com acesso pela rodovia PRT 280 (Rodovia Manoel L. Martins) em direção à região sudoeste do Estado do Paraná, percorrendo $8,8 \mathrm{Km}$ de asfalto e mais $1,2 \mathrm{Km}$ em estrada secundária de terra, nas coordenadas UTM 392.634.827 E, 7.071.857.644 N (Figura1).

\subsection{Geologia}

Localizada na porção sul do Terceiro Planalto Paranaense, a área em questão, se dispõe sobre rochas do Grupo São Bento - Formação Serra Geral, ou seja, derrames basálticos e rochas intrusivas básicas e, principalmente pelas rochas ácidas do tipo Palmas.

A área conhecida como "Lixão de Palmas", assenta-se sobre riolitos do Mesozóico da Bacia do Paraná, pertencentes à unidade litoestratigráfica reconhecida por Nardy (1995) como Membro Palmas. O Membro Palmas (riolitos e riodacitos), refere-se às rochas ácidas do tipo Palmas que ocorrem na forma de corpos de platôs ao sul do rio Iguaçu, distribuindo-se nos altos topográficos de Palmas, Bituruna, General Carneiro e Matos Costa.

As rochas ácidas tipo Palmas, segundo BARFKNECHT (in KRÜGER,2002), caracterizam-se por apresentarem granulações mineralógicas extremamente finas, afaníticas, muitas vezes com abundante massa vítrea, características de rápido resfriamento e algumas vezes, estruturas de fluxo, resultantes da movimentação da massa que se solidificava. Mostram-se as litologias freqüentemente "mosqueadas", devido à tonalidade dos grupos minerais formadores serem ora claros, ora escuros, freqüentemente com pontos escuros (minerais máficos) imersos em abundante matriz clara.

Como uma capa ácida sobre derrames basálticos (básicos), as rochas ácidas tipo Palmas, coroam topograficamente toda a região (Campos de Palmas de Cima) tendo como limites às proximidades da cidade de 


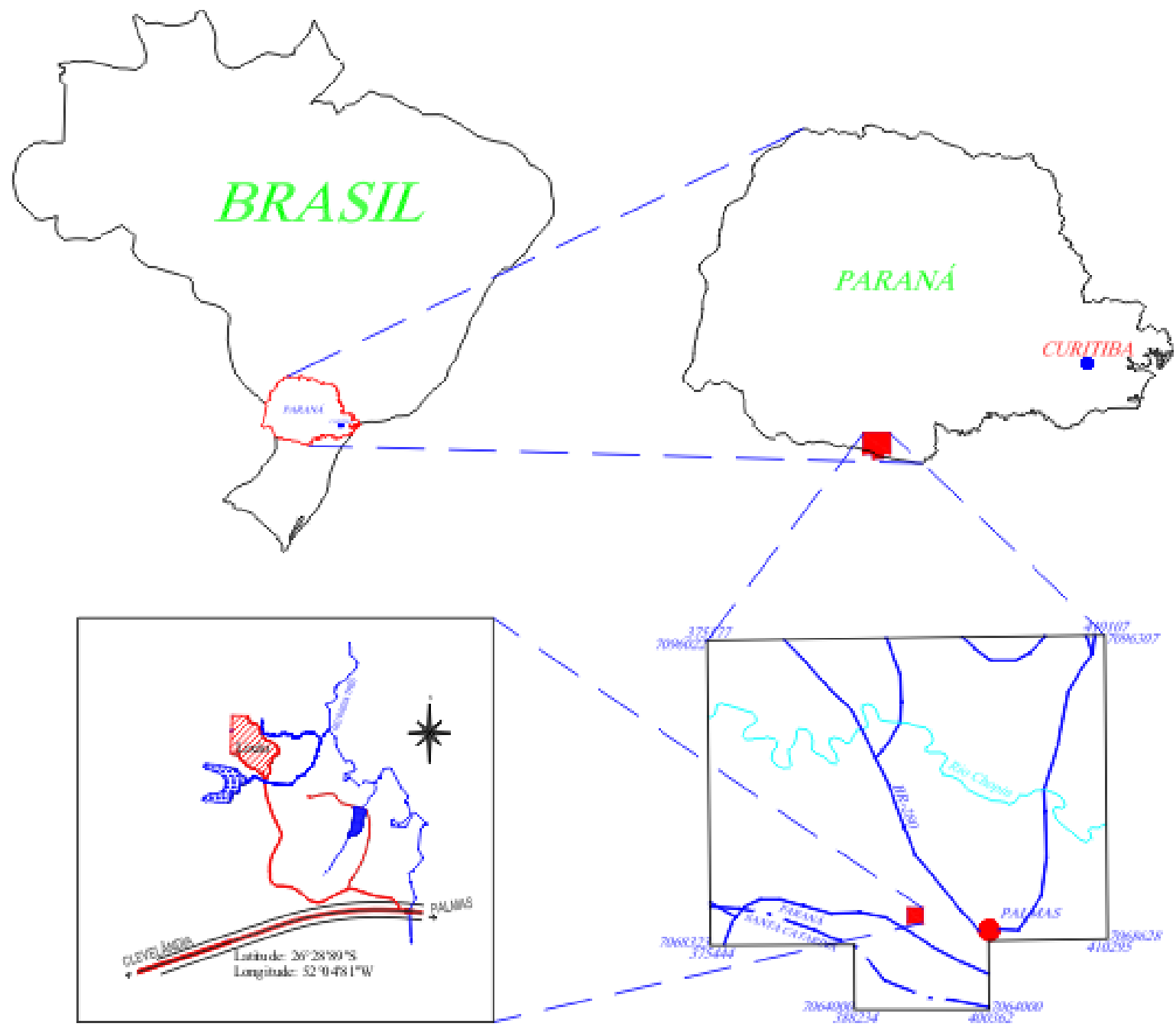

Figura 1 - Mapa de Localização do Depósito de Lixo.

Palmas a oeste e os vales bastante encaixados dos Rios Iratim-Iguaçu ao norte. Os limites com os termos básicos ocorrem nas vertentes deste degrau, nas proximidades do Trevo da BR-153 e PR-280. Os limites ao sul, ocorrem nos municípios de Água Doce e Passos Maia, sem que ocorram particularidades topográficas, como nos outros limites, já que as altitudes decrescem gradualmente em todas as direções a partir das proximidades do trevo entre a BR-153 e PR-280, expondo outros derrames mais antigos, preferencialmente basálticos.

\subsection{Clima}

De acordo com a classificação climática de Koeppen, o clima local é definido como Cfb, ou seja, clima subtropical úmido mesotérmico, com verões frescos (temperatura média inferior a $22^{\circ} \mathrm{C}$ ) e invernos com ocorrências de geadas freqüentes e severas (temperatura média inferior a $18^{\circ} \mathrm{C}$ ), chegando a nevar em alguns anos (MAACK, 2002).

Segundo dados fornecidos pelo Instituto Agronômico do Paraná - IAPAR, no período de 1979 a 2002, as temperaturas médias dos meses de janeiro e julho foram de $20,3^{\circ} \mathrm{C}$ e $11,6^{\circ} \mathrm{C}$ respectivamente. Chove em média 144 dias por ano, segundo as estatísticas dos últimos 24 anos sendo a precipitação pluviométrica média anual de $2.154 \mathrm{~mm}$ para o período considerado.

\subsection{Solos}

Predominam na área de estudo solos do tipo Cambissolo Háplico Alumínico, Neossolo Litólico e Latossolo Bruno Alumínico (EMBRAPA, 1984, 1999).

Tais solos apresentam textura essencialmente argilosa e argilo-siltosa, como pôde ser observado através da realização de análises granulométricas realizadas em quatro perfis na área de estudo, com os teores de argila variando entre 40 e $60 \%$ e espessuras de 1 a $2,5 \mathrm{~m}$.

\section{Materiais e métodos}

\subsection{Levantamento Geofísico}

Atualmente, alguns métodos geofísicos vêm sendo usados para detectar e monitorar a contaminação gerada pelo chorume resultante dos líquidos percolados em áreas de depósito de resíduos urbanos e industriais. Dentre os principais métodos geofísicos de investigação, para o estudo das estruturas geológicas da parte superior da crosta terrestre, destacam-se os métodos geoelétricos, os 
quais se fundamentam na análise de campos elétricos e eletromagnéticos. As rochas, em função de suas composições mineralógicas, textura, porosidade e permeabilidade aliadas ao grau de saturação por água, apresentam propriedades elétricas características, dentre as quais a resistividade.

Trabalhos recentes têm demonstrado a grande eficiência e versatilidade da eletrorresistividade, fornecendo informações importantes em estudos ambientais, como no caso de contaminação provocada por depósitos de lixo (HYOUNG-SOO \& YEONGHWA,1997).

Em estudos para neutralização de impactos ambientais gerados pelo "Lixão da Lamenha Pequena", região metropolitana de Curitiba, Paraná, RIGOTI (1997) demonstrou que o método da eletrorresistividade pode ser usado para mapeamento do corpo do lixão tanto lateralmente como em profundidade e ainda mapear os caminhos preferenciais dos fluidos contaminantes a jusante do depósito de lixo.

A fim de se investigar a resistividade dos materiais e a possibilidade de contaminação por chorume, o levantamento geofísico na área do Lixão de Palmas consistiu em caminhamento elétrico, arranjo dipolo-dipolo, com cerca de 20 níveis de investigação, na técnica de imageamento ou levantamento $2 \mathrm{D}$ de fato, gerando uma imagem detalhada da seção geoelétrica até aproximadamente 50 metros de profundidade. Assumindo uma distribuição de resistividade 2D, as pseudo-seções foram modeladas numericamente para determinar a seção "real", ou uma seção modelo que, numericamente, produz uma seção de resistividade aparente que se compara tão bem quanto possível à observada. Este processo de modelagem é conhecido como inversão na geofísica. O programa RES2DINV de LOKE (1999) recentemente modificado pela Advanced Geoscience Incorporation, com o nome Earthimager, foi utilizado para esta modelagem no presente estudo. Foram realizadas 5 linhas de caminhamento elétrico com espaçamento variável de até 10 metros entre os eletrodos, denominadas de L1 a L5. Cada linha teve 240 metros de extensão. Entre L1 e L2, paralelas entre si, a distância foi de $15 \mathrm{~m}$. Assim também entre L3 e L4 a distância foi de $15 \mathrm{~m}$.

A técnica do caminhamento elétrico se baseia na análise e interpretação da resistividade, a partir de medidas efetuadas na superfície do terreno, investigando, ao longo de uma seção, sua variação na horizontal, a uma ou mais profundidades determinadas. O arranjo dipolo-dipolo revela-se como um dos mais apropriados para o estudo de contaminações. Uma de suas grandes vantagens reside no fato de que, o estudo da variação lateral do parâmetro físico pode ser efetuado em vários níveis de profundidades, obtendo-se uma caracterização dos materiais, em subsuperfície, tanto horizontalmente como verticalmente. Esta característica do dipolo-dipolo é importante em estudos ambientais, onde a caracterização de uma pluma de contaminação pode ser estudada lateralmente e em profundidade.
A Figura 2 ilustra a disposição das linhas geofísicas na área de estudo.

\subsection{Análise Hidroquímica}

Para a caracterização dos corpos hídricos superficiais situados na área de depósito de lixo de Palmas - PR e seu entorno, foram realizadas duas campanhas amostrais, uma em estação seca e outra em estação chuvosa. Foram selecionados cinco pontos de amostragem, sendo três nas drenagens que circundam o lixão e dois no rio Passa Três, um a montante e outro a jusante do ponto de descarga das drenagens que passam pelo depósito de lixo. Para a escolha dos pontos de amostragem levou-se em consideração a inserção do lixão nas sub-bacias hidrográficas, ou seja, o critério de recorte espacial da bacia hidrográfica.

Foram analisados: $\mathrm{pH}$, condutividade, temperatura da água, temperatura ambiente, alcalinidade total, dureza total, nitrogênio total, nitrogênio orgânico, nitrogênio amoniacal, nitrato, nitrito, sólidos totais, DBO, DQO, sílica, bicarbonato, cloreto, sulfato, cálcio, magnésio, sódio, potássio, ferro total, alumínio, cádmio, chumbo, cromo total, cobre, manganês, zinco, coliformes totais e coliformes fecais. Temperatura do ar, temperatura da água e $\mathrm{pH}$ foram obtidos em campo. As demais variáveis foram analisadas no Laboratório de Pesquisas Hidrogeológicas (LPH) da UFPR, utilizando-se metodologia preconizada no "Standard Methods for the Examination of Water and Wastewater, $20^{\text {th }}$ Edition 1998" (APHA, 1998).

A Figura 3 ilustra a disposição dos pontos de amostragem de água na área de estudo.

\section{Resultados e discussão}

A Figura 4 representa a seção modelo de resistividade obtida nos ensaios de caminhamento elétrico para a linha L1, onde se observam fortes variações de resistividade, podendo-se inferir que as regiões de alta resistividade (valores representados em laranja e vermelho) representam cobertura seca, aerada, resultante de solos argilosos e argilo-siltosos de rochas da Formação Serra Geral. Os núcleos em vermelho, cujos valores de resistividade se aproximam de $2000 \Omega$.m refletem rocha sã, mais preservada. As variações nos valores de resistividade da rocha ocorrem em função de variação do grau de fraturamento, porosidade, permeabilidade e a conseqüente alteração da mesma e possível saturação por água.

A interface amarelo/verde na Linha 1, com diminuição significativa da resistividade, indica que nesta profundidade atinge-se o nível d'água (NA). A zona saturada, representada pelos valores de baixa resistividade em tons azuis demonstra o sentido natural do fluxo, acompanhando a declividade do terreno. A zona de baixa de resistividade

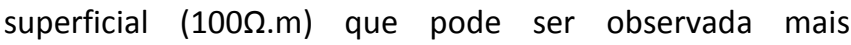
notadamente na Linha 1, entre as estações $177 \mathrm{~m}$ e $197 \mathrm{~m}$ é interpretada como zona de maior saturação, associada à drenagem situada nas proximidades do lixão. Abaixo desse ponto, na profundidade situada entre $15 \mathrm{~m}$ e $20 \mathrm{~m}$, os 


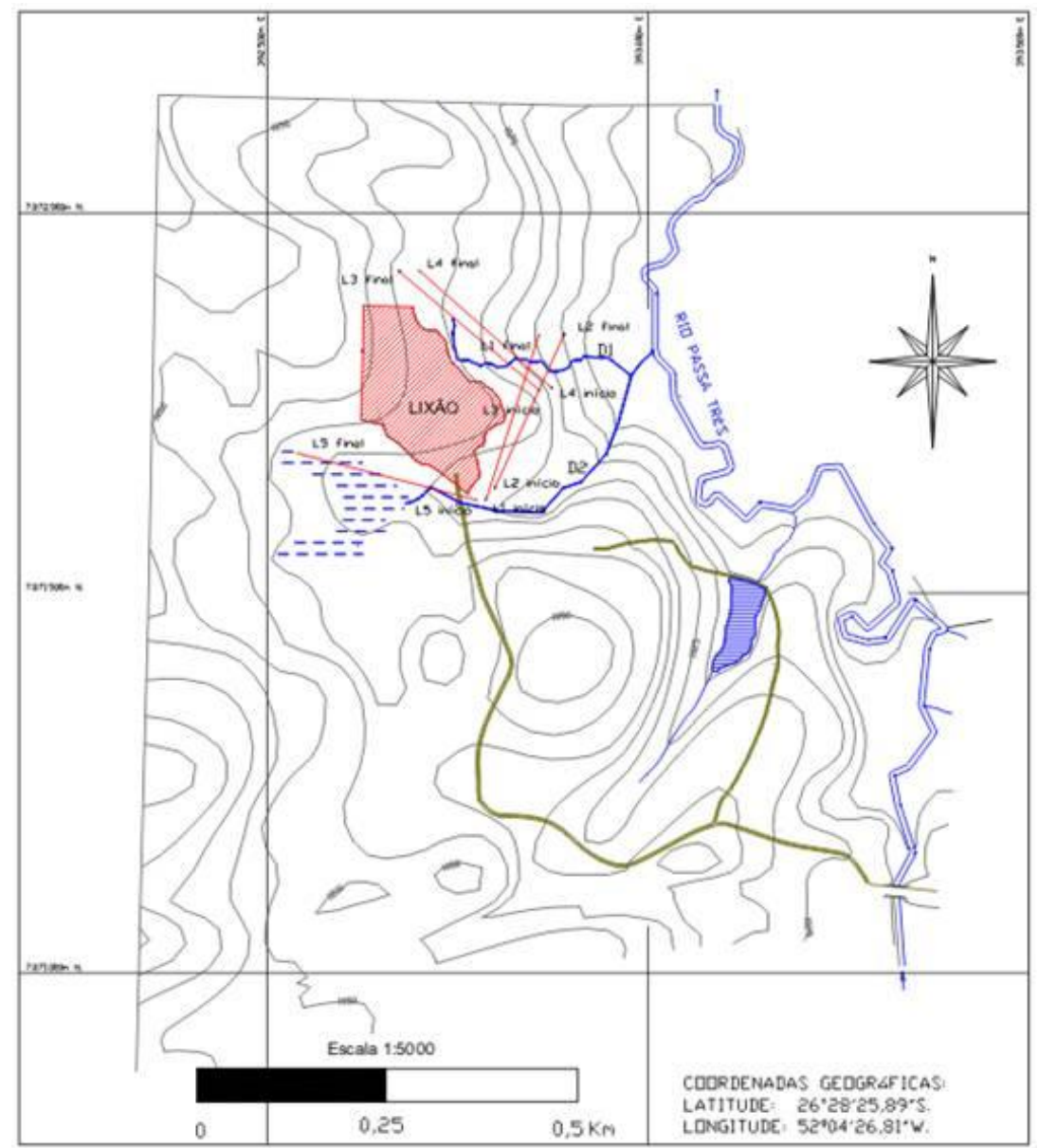

Figura 2 - Mapa de localização das linhas geofísicas.

valores de resistividade são ainda menores (entre 6,0 e $30 \Omega . m$ ) e sugerem a presença de contaminantes oriundos do depósito de lixo. Ainda, de acordo com o ensaio realizado, ocorre uma faixa condutora mais superficial, com valores de resistividade situados entre 20 e $60 \Omega . \mathrm{m}$, situada entre as estações $30 \mathrm{~m}$ e $80 \mathrm{~m}$ na seção modelo da linha L1 e que se prolonga em profundidades maiores, a qual pode ser interpretada como uma região mais vulnerável que pode estar sofrendo a influência, em maior ou menor grau, da presença de líquidos percolantes provenientes do lixão.

Notadamente na linha L3 (Figura 5) entre as estações $40 \mathrm{~m}$ e $90 \mathrm{~m}$, nas proximidades da drenagem que circunda o lixão, encontram-se valores de resistividade bem baixos, menores que 10?. $\mathrm{m}$, sugerindo a percolação de fluidos condutores através do substrato geológico, tendo em vista que, logo acima deste ponto encontra-se o depósito de resíduos mais antigos e que teria dado início ao lixão, o que pode ser comprovado pela grande quantidade de vidros e metais oxidados dispostos sobre o solo.

A realização de análises de água superficial na drenagem acima referida, particularmente em período chuvoso, evidenciou a presença de contaminantes diversos, cujas concentrações encontram-se detalhadas nas Tabelas 1 e 2. Apesar da contaminação ser incipiente e os valores na maioria das vezes não ultrapassarem o que determina a Resolução CONAMA (2005) para águas superficiais, os resultados confirmam a modelagem descrita.
A região de baixa resistividade compreendida entre as estações 170 e 210 metros na Linha 3 pode estar relacionada à presença de material argiloso em prováveis fraturamentos na área, os quais seriam caminhos preferenciais de percolação de água e de desenvolvimento de argilas. Pelas evidências da geomorfologia, a não ser via fraturas que comuniquem o lixão em maiores profundidades, é pouco provável a influência do depósito de lixo neste local.

A seção de resistividade obtida pela inversão da Linha 5 mostra uma zona condutora mais superficial desde o início da linha até o eletrodo de número 6 no campo (Figura 6 L5 - Estação 50m). Tal feição corresponde à mesma encontrada na Linha 1 já citada anteriormente (entre as estações 30 e $80 \mathrm{~m}$ ) e que foi interpretada como sendo a zona de maior vulnerabilidade, influenciada por fluidos mais condutivos originários no depósito de lixo. Observamse, dentro da zona saturada, regiões de menor resistividade nas posições entre 60 e 79 metros e 99 e 139 metros; esta última chegando a atingir 50 metros de profundidade. A proximidade com a drenagem e a topografia local, sugere uma provável contaminação gerada pela migração do percolado proveniente dos resíduos sólidos dispostos na área, porém a investigação direta por meio da instalação de poços de monitoramento em tais locais é ferramenta importante para a confirmação da contaminação. 


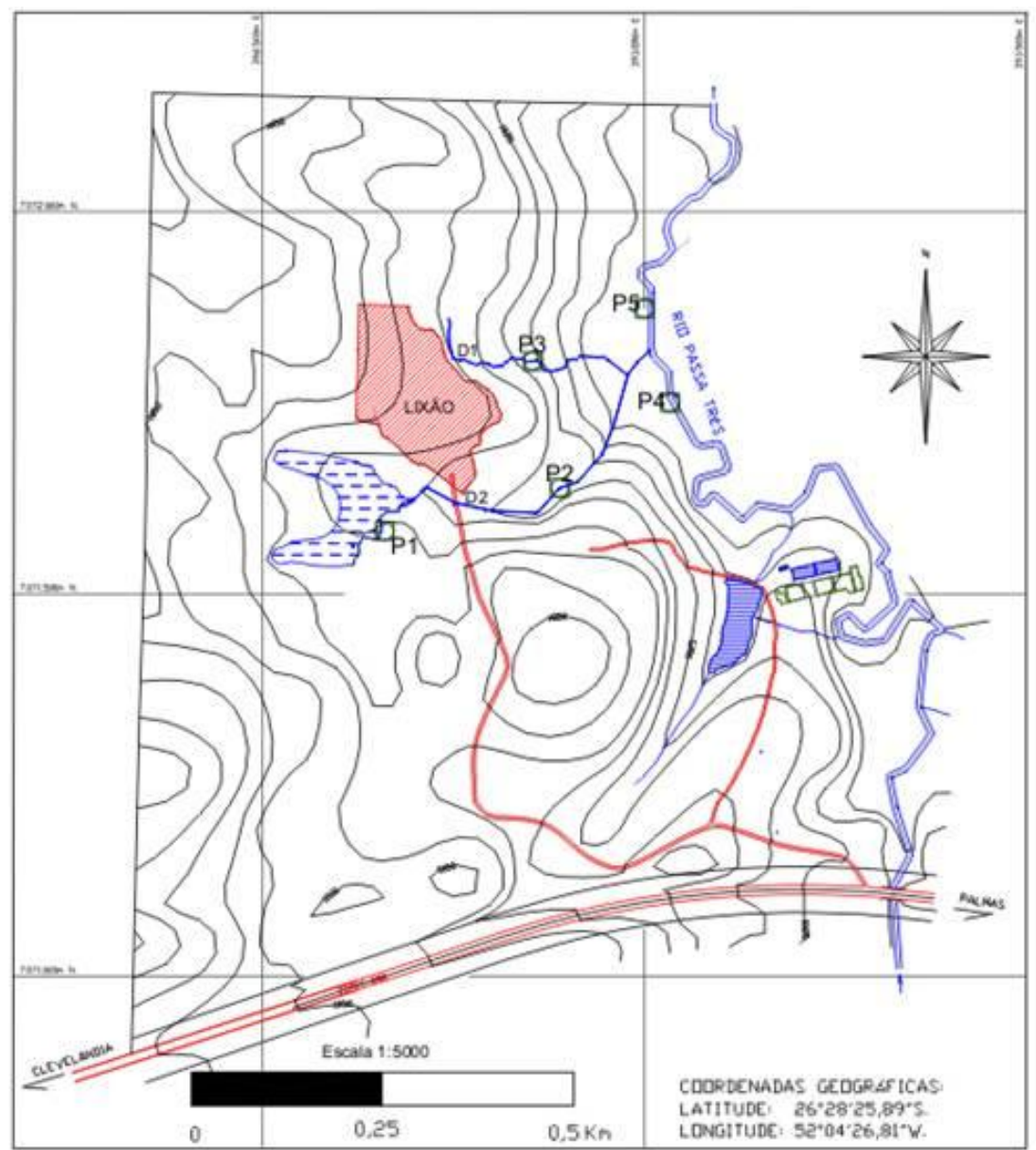

Figura 3 - Mapa de localização dos pontos de amostragem de água.

LIXÃo DE PALMAS - L1 - SEÇÃO MODELO DE RESISTIVIDADE

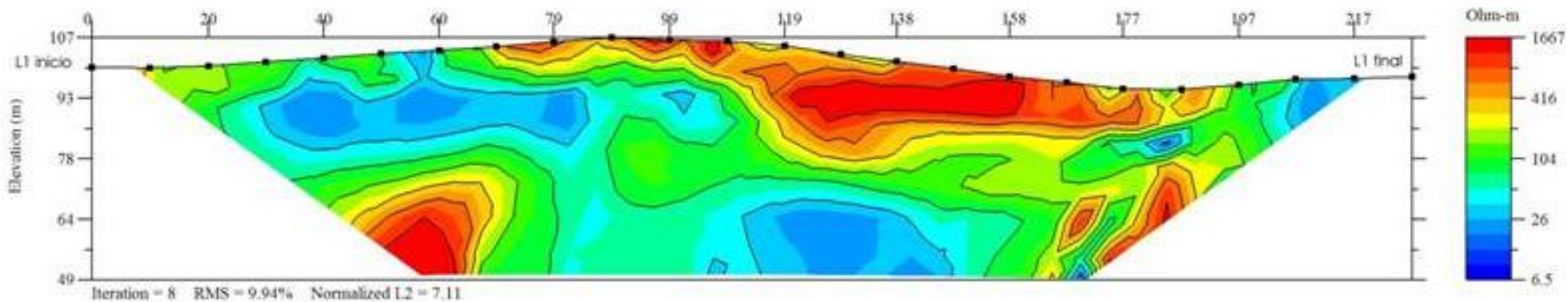

Figura 4 - Seção Modelo de Resistividade da Linha 1.

LIXĀO DE PALMAS - L3 - SEÇÃo MODEL DE RESISTIVIDADE

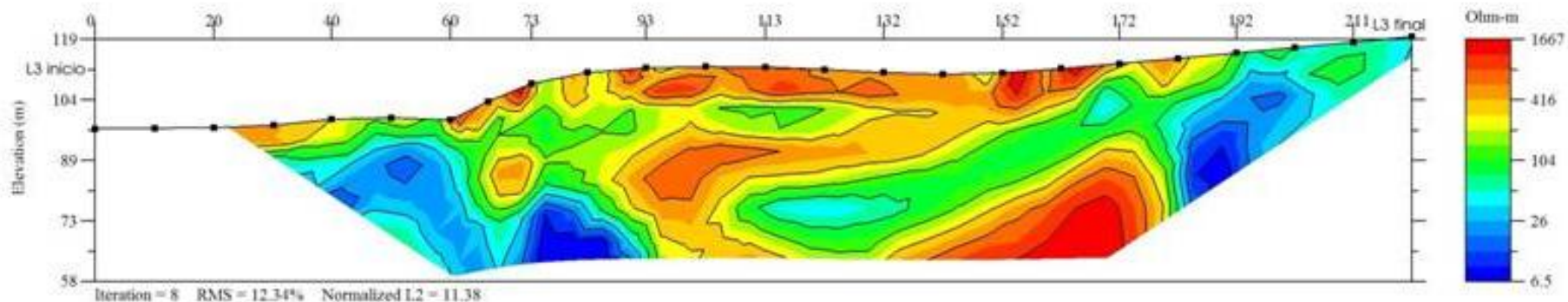

Figura 5 - Seção Modelo de Resistividade da Linha 3. 
LXXÁO DE PALMAS - L.5 - SEÇȦO MODELL DE RESISTIVIDADE

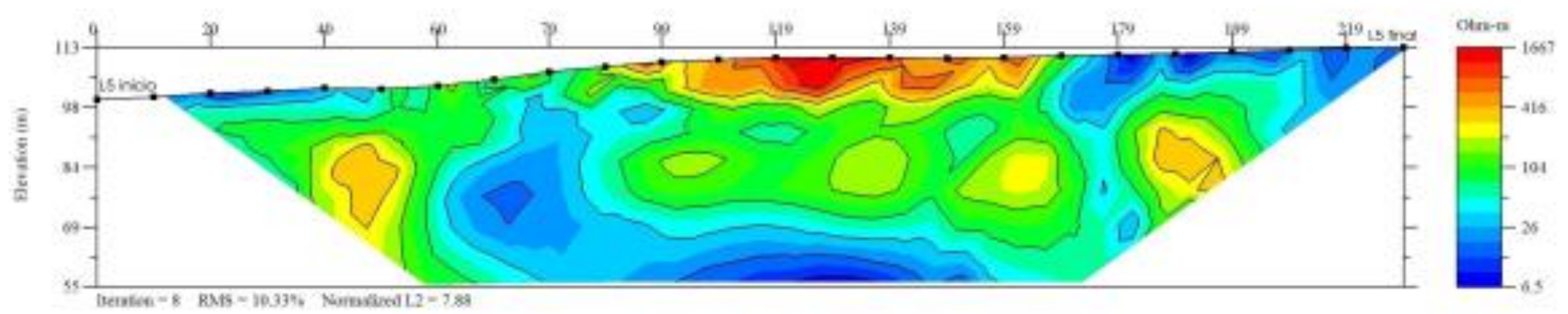

Figura 6 - Seção Modelo de Resistividade da Linha 5.

Com o auxílio das Tabelas 1 e 2 pode-se visualizar o resultado das análises físicas, químicas e bacteriológicas nos pontos P1, P2 e P3 (drenagens que circundam o depósito de lixo) e P4 e P5 (Rio Passa Três), nos períodos seco e chuvoso, respectivamente.

O comportamento da condutividade está relacionado à concentração de sólidos totais. Para as duas variáveis analisadas percebe-se um aumento significativo de valores no Ponto 3 (drenagem), de modo mais intenso na estação chuvosa, como conseqüência do escorrimento superficial. Especificamente para este ponto, está havendo uma maior contribuição de sólidos dissolvidos provenientes do lixão que estão atingindo as águas superficiais por ocasião das chuvas, aumentando assim os valores de condutividade (Figura 7).

Tabela 1 - Composição química da água superficial na área de depósito de lixo de Palmas - PR e seu entorno em estação seca.

\begin{tabular}{|l|r|r|r|r|r|}
\hline Parâmetros & Ponto 1 & Ponto 2 & Ponto 3 & Ponto 4 & Ponto 5 \\
\hline $\mathrm{pH}$ & 5,7 & 5,8 & 6,1 & 6,7 & 6,7 \\
\hline Condutividade & 12,7 & 21,8 & 26,9 & 31,8 & 30,8 \\
\hline Temperatura do ar ${ }^{\circ} \mathrm{C}$ & 23,5 & 29 & 22 & 27 & 25 \\
\hline Temperatura da água ${ }^{\circ} \mathrm{C}$ & 12,1 & 12,9 & 12,8 & 13,2 & 12,7 \\
\hline Alcalinidade total $(\mathrm{mg} / \mathrm{L})$ & 4,26 & 6,86 & 3,96 & 13,96 & 14,84 \\
\hline Dureza total $(\mathrm{mg} / \mathrm{L})$ & 2,37 & 5,26 & 5,56 & 11,53 & 11,84 \\
\hline Nitrogênio Kjeldahl total (mg/L) & $<0,01$ & $<0,01$ & $<0,01$ & 0,14 & 0,1 \\
\hline Nitrogênio amoniacal (mg/L) & $<0,01$ & $<0,01$ & $<0,01$ & 0,08 & 0,03 \\
\hline Nitrogênio orgânico (mg/L) & $<0,01$ & $<0,01$ & $<0,01$ & 0,06 & 0,07 \\
\hline Sólidos totais (mg/L) & 8 & 14 & 18 & 21 & 20 \\
\hline Sólidos suspensos totais(mg/L) & $<5$ & $<5$ & $<5$ & $<5$ & $<5$ \\
\hline Sólidos dissolvidos totais(mg/L) & 8 & 14 & 18 & 21 & 20 \\
\hline DBO $(\mathrm{mg} / \mathrm{L})$ & $<10$ & $<10$ & $<10$ & $<10$ & $<10$ \\
\hline DQO $(\mathrm{mg} / \mathrm{L})$ & $<10$ & $<10$ & $<10$ & $<10$ & $<10$ \\
\hline Bicarbonatos (mg/L) & 5,2 & 8,4 & 4,83 & 17,3 & 18,1 \\
\hline Cloretos (mg/L) & 0,8 & 3,4 & 7,27 & 1,05 & 0,89 \\
\hline Fosfatos (mg/L) & 0,13 & 0,04 & 0,08 & 0,11 & 0,12 \\
\hline Sulfatos (mg/L) & $<1$ & $<1$ & $<1$ & $<1$ & $<1$ \\
\hline Nitratos (mg/L) & $<0,04$ & 0,35 & 1,06 & 1,72 & 1,81 \\
\hline Nitritos(mg/L) & $<0,01$ & $<0,01$ & $<0,01$ & $<0,01$ & $<0,01$ \\
\hline Cálcio(mg/L) & 0,8 & 2,02 & 2,1 & 4,45 & 4,17 \\
\hline Magnésio(mg/L) & 0,09 & 0,04 & 0,07 & 0,09 & 0,34 \\
\hline Sódio(mg/L) & 1,2 & 2,4 & 3,6 & 2,2 & 2,3 \\
\hline Potássio(mg/L) & 0,9 & 1,7 & 2,4 & 1,3 & 1,4 \\
\hline Ferro total(mg/L) & 0,28 & 0,46 & 0,13 & 0,49 & 0,44 \\
\hline Alumínio(mg/L) & 1,02 & 1,23 & 0,19 & 0,36 & 0,46 \\
\hline Cádmio(mg/L) & $<0,001$ & 0,002 & $<0,001$ & $<0,001$ & $<0,001$ \\
\hline Chumbo(mg/L) & $<0,05$ & $<0,05$ & $<0,05$ & $<0,05$ \\
\hline Cromo total(mg/L) & $<0,01$ & $<0,01$ & $<0,01$ & $<0,01$ & $<0,01$ \\
\hline Cobre(mg/L) & $<0,01$ & $<0,01$ & $<0,01$ & 0,04 & 0,04 \\
\hline Manganês(mg/L) & 0,01 & 0,05 & 0,01 & 0,06 & 0,02 \\
\hline Zinco(mg/L) & 52419,2 & $>2419,2$ & $>2419,2$ & 1732,87 & 1413,87 \\
\hline Coliformes totais NMP/100mL & 36,3 & 78,9 & 52 & 55,2 \\
\hline Coliformes fecais NMP/100mL & & & & $<0,06$ \\
\hline
\end{tabular}


Tabela 2 - Composição química da água superficial na área de depósito de lixo de Palmas - Pr e seu entorno em estação chuvosa.

\begin{tabular}{|l|r|r|r|r|r|}
\hline Parâmetros & Ponto 01 & Ponto 02 & Ponto 03 & Ponto 04 & Ponto 05 \\
\hline pH & 5,5 & 5,9 & 5,9 & 6,7 & 6,6 \\
\hline Condutividade & 11,6 & 20,5 & 39,7 & 36,2 & 33,1 \\
\hline Temperatura do ar ${ }^{\circ} \mathrm{C}$ & 22 & 24,5 & 21 & 24,5 & 23 \\
\hline Temperatura da água ${ }^{\circ} \mathrm{C}$ & 14,1 & 14,7 & 13,7 & 16,3 & 15,4 \\
\hline Alcalinidade total $(\mathrm{mg} / \mathrm{L})$ & 9,25 & 10,98 & 8,91 & 18,81 & 15,84 \\
\hline Dureza total $(\mathrm{mg} / \mathrm{L})$ & 6,48 & 6,07 & 5,77 & 15,99 & 14,07 \\
\hline Nitrogênio Kjeldahl total $(\mathrm{mg} / \mathrm{L})$ & $<0,01$ & $<0,01$ & $<0,01$ & $<0,01$ & $<0,01$ \\
\hline Nitrogênio amoniacal(mg/L) & $<0,01$ & $<0,01$ & $<0,01$ & $<0,01$ & $<0,01$ \\
\hline Nitrogênio orgânico(mg/L) & $<0,01$ & $<0,01$ & $<0,01$ & $<0,01$ & $<0,01$ \\
\hline Sólidos totais (mg/L) & 70 & 72 & 135 & 75 & 73 \\
\hline Sólidos suspensos totais(mg/L) & 36 & 34 & 93 & 40 & 35 \\
\hline Sólidos dissolvidos totais(mg/L) & 34 & 38 & 42 & 35 & 38 \\
\hline DBO(mg/L) & $<10$ & $<10$ & 12 & $<10$ & $<10$ \\
\hline DQO(mg/L) & 22 & $<10$ & 30 & $<10$ & $<10$ \\
\hline Sílica(mg/L) & 20,3 & 21,7 & 13,3 & 14,6 & 15 \\
\hline Bicarbonatos(mg/L) & 11,1 & 13,4 & 10,87 & 22,95 & 19,32 \\
\hline Cloretos(mg/L) & 0,83 & 1,78 & 10,16 & 0,83 & 1,39 \\
\hline Sulfatos(mg/L) & $<1$ & $<1$ & $<1$ & $<1$ & $<1$ \\
\hline Nitratos (mg/L) & $<0,04$ & 0,4 & 1,72 & 2,12 & 2,08 \\
\hline Nitritos(mg/L) & $<0,01$ & $<0,01$ & $<0,01$ & $<0,01$ & $<0,01$ \\
\hline Cálcio(mg/L) & 1,3 & 1,25 & 2,02 & 3,16 & 3,24 \\
\hline Magnésio(mg/L) & 0,78 & 0,7 & 0,17 & 1,94 & 1,43 \\
\hline Fosfatos (mg/L) & 0,18 & 0,11 & 0,19 & 0,15 & 0,15 \\
\hline Sódio(mg/L) & 1,2 & 2,1 & 4,8 & 1,8 & 1,5 \\
\hline Potássio(mg/L) & 0,9 & 1,8 & 3,6 & 1,9 & 1,6 \\
\hline Ferro total(mg/L) & 0,6 & 0,95 & 2,05 & 1,15 & 0,95 \\
\hline Alumínio(mg/L) & 0,41 & 0,4 & 0,63 & 0,03 & 0,3 \\
\hline Cádmio(mg/L) & $<0,05$ & $<0,05$ & $<0,05$ & $<0,05$ & $<0,05$ \\
\hline Chumbo(mg/L) & $<0,06$ & $<0,06$ & $<0,06$ & $<0,06$ & $<0,06$ \\
\hline Cromo total(mg/L) & $<0,01$ & $<0,01$ & $<0,01$ & $<0,01$ & $<0,01$ \\
\hline Cobre(mg/L) & $<0,01$ & $<0,01$ & 0,44 & 0,02 & 0,03 \\
\hline Manganês(mg/L) & $<0,01$ & $<0,01$ & $<0,01$ & $<0,01$ & $<0,01$ \\
\hline Zinco(mg/L) & 1239 & 11198,5 & $>24192$ & 19862,8 & 15530,7 \\
\hline Coliformes totais NMP/100mL & 262 & 262 & 439 & 213 \\
\hline Coliformes fecaisNMP/100mL & & & & \\
\hline
\end{tabular}

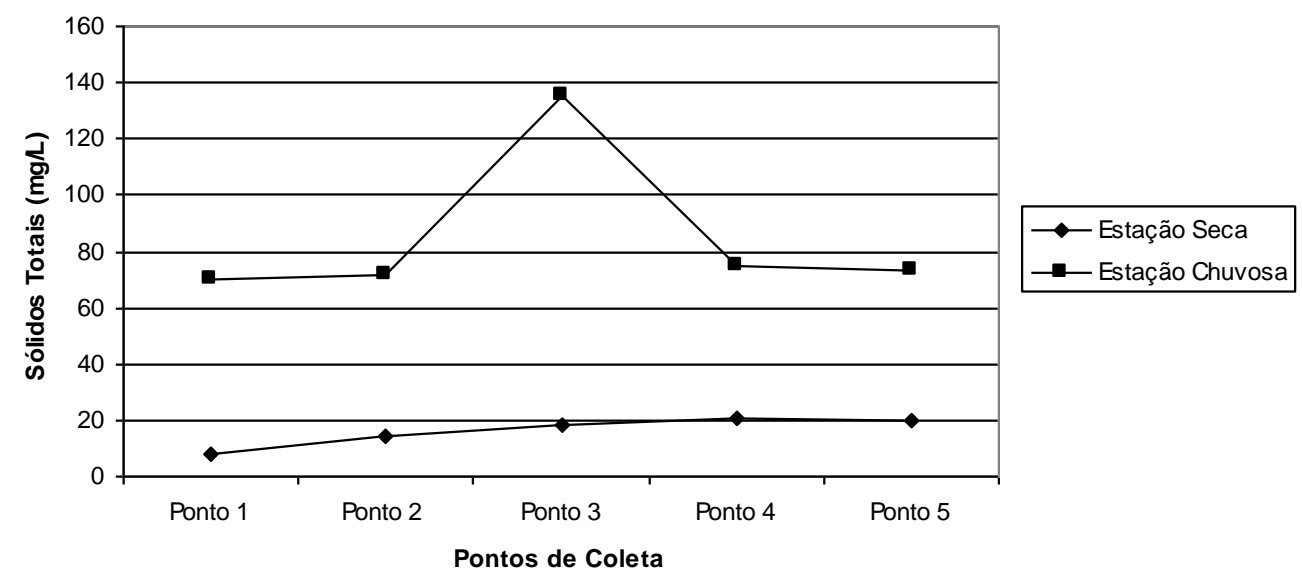

Figura 7 - Valores de Sólidos Totais encontrados nas águas superficiais da área do Lixão de Palmas - PR (mg/L).

Com relação ao nitrogênio, a espécie química predominante encontrada nas águas analisadas, conforme pode ser observado nas Tabelas 1 e 2 foi a de nitrato. 0 nitrito não foi observado e o nitrogênio amoniacal apareceu em pequenas concentrações no Rio Passa Três. Pode-se observar pelo gráfico da Figura 8 um aumento crescente na concentração de nitrogênio total nos pontos de coleta ao longo das drenagens para o Rio Passa Três, portanto, indicando que a influência do lixão é pouco significativa em relação a este parâmetro na qualidade das águas superficiais. Outras fontes antropogênicas ao longo da Bacia do Rio Passa Três estão contribuindo mais 


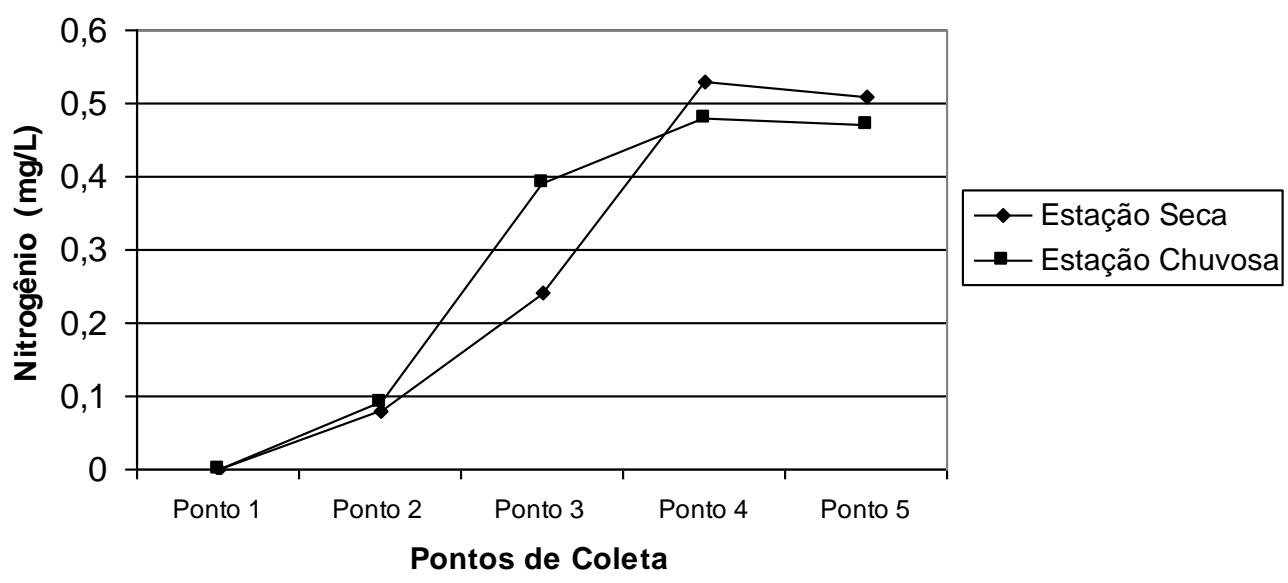

Figura 8 - Nitrogênio Total encontrado nas águas superficiais da área do Lixão de Palmas - PR(mg/L).

significativamente com a presença deste elemento nas águas. Apesar disso, a concentração das espécies de nitrogênio em todos os pontos é inferior aos limites estabelecidos pela legislação vigente (CONAMA, 2005) para um rio de classe 2 .

A sazonalidade exerceu influência sobre os parâmetros DBO e DQO. Em estação seca não foram observados, porém em estação chuvosa aumentou o consumo de oxigênio em alguns pontos, mais especificamente no Ponto 3 . Credita-se que este aumento, tanto de DBO quanto de DQO no referido ponto, a poluição orgânica proveniente do lixão.

Quanto aos padrões de potabilidade de água, a Portaria no 36 (BRASIL, 2001), não estabelece um valor limite para DBO. Porém, McGAUHEY (1968) estabelece valores limites de 3,0 a 5,0 mg/L em termos de DBO para rios de classe $D$, considerados de má qualidade. No Ponto 3 o valor encontrado ultrapassou esse limite $(12 \mathrm{mg} / \mathrm{L})$.
Os valores encontrados para cloreto, como pode ser observado pelo gráfico da Figura 9, são inferiores ao limite máximo permitido pela legislação CONAMA (2005), contudo há um aumento considerável nas concentrações no Ponto 3, em relação aos demais pontos, podendo ser indicativo de poluição localizada proveniente do lixão. No contexto geológico regional, a contribuição potencial de cloreto pelas rochas é reduzida, restando as fontes por aerossóis e contaminação por atividade antrópica.

Monitoramentos de águas em áreas adjacentes a lixões e análises de chorume em Aterros Sanitários têm evidenciado a presença de altos valores de cloreto, se constituindo em um indicador de poluição pelo lixo (PARISOT, 1985; SANTOS et al, 2003).

Embora o comportamento geoquímico dos íons sódio e potássio seja com freqüência diferente, nas águas analisadas mostrou-se semelhante (Figura10), semelhança esta aumentada pela influência do escorrimento superficial.

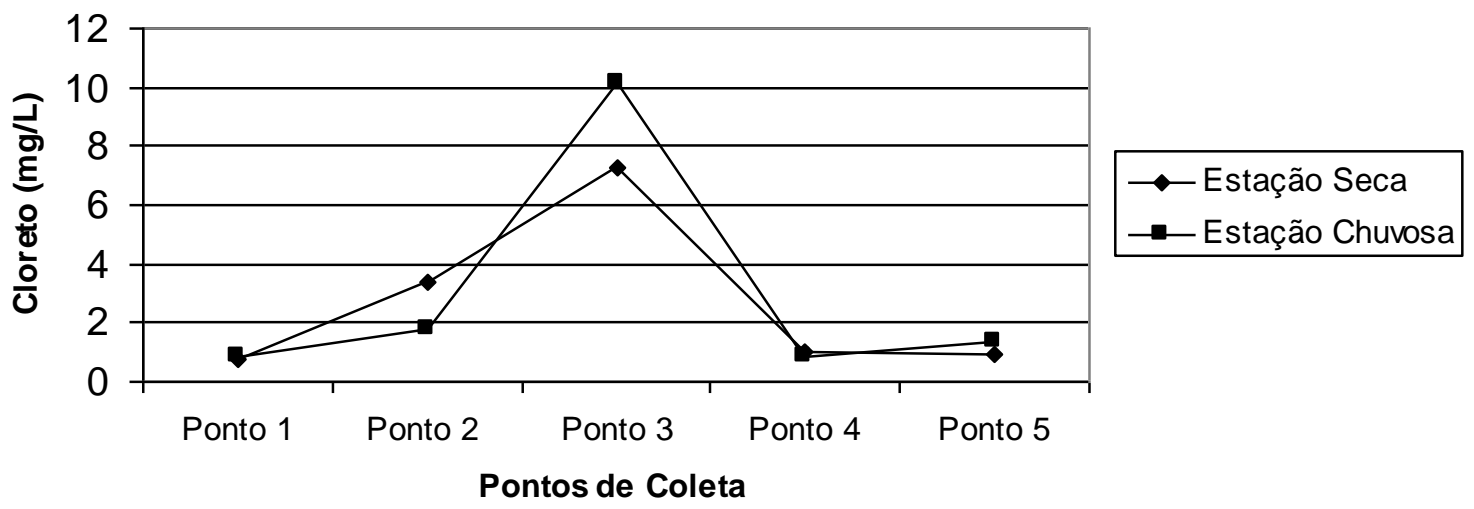

Figura 9 - Valores de Cloreto encontrados nas águas superficiais da área do Lixão de Palmas - PR (mg/L). 


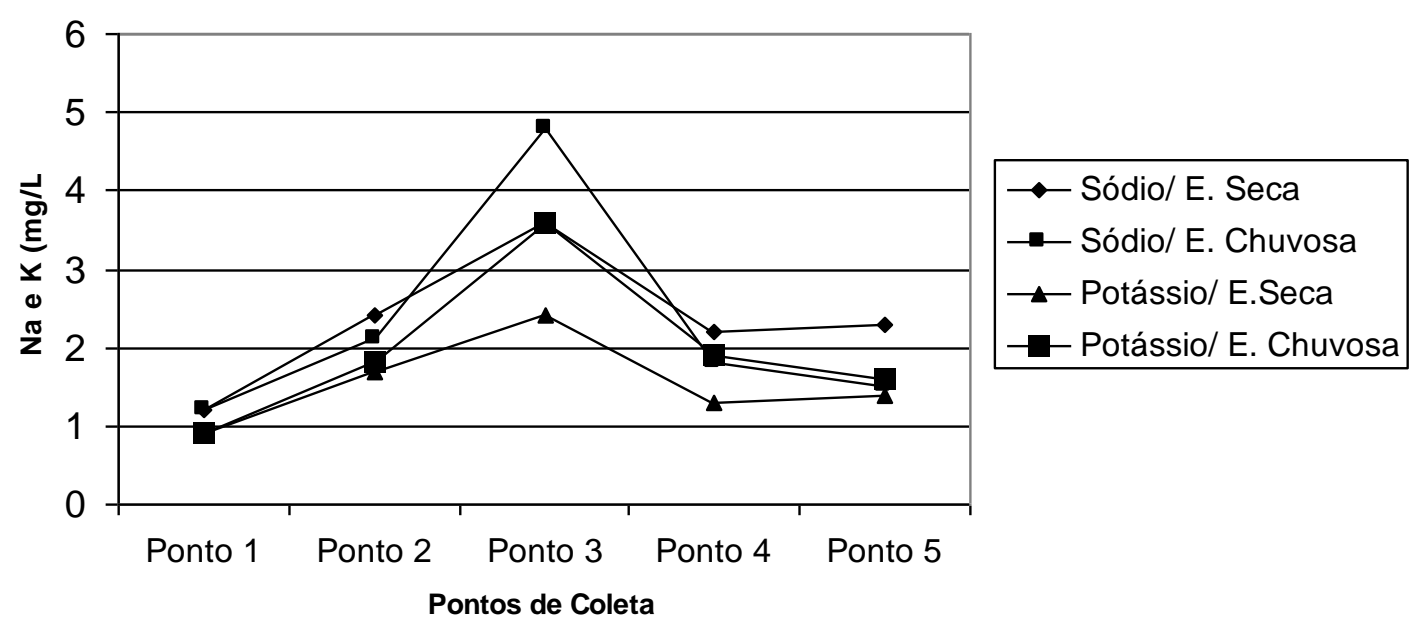

Figura 10 - Níveis de Sódio e Potássio encontrados nas águas superficiais da área do Lixão de Palmas - PR (mg/L).

A análise do gráfico permite verificar que sódio e potássio apresentam um pico de concentração no Ponto 3, assim como outras variáveis anteriormente analisadas.

Os valores médios encontrados foram de $2,3 \mathrm{mg} / \mathrm{L}$ para o sódio e $1,2 \mathrm{mg} / \mathrm{L}$ para o potássio. BITTENCOURT (1982) determinou em drenagens sobre basaltos da Formação Serra Geral na bacia do rio Ivaí - Paraná, valores médios de $1,92 \mathrm{mg} / \mathrm{L}$ e $1,14 \mathrm{mg} / \mathrm{L}$ para sódio e potássio, respectivamente. GIBBS (1972) estabelece valores médios de 4,9 e 1,5 mg/L respectivamente para sódio e potássio para os rios da América do Sul. Embora os valores encontrados nas águas superficiais sejam próximos dos valores sugeridos por estes autores, percebe-se uma influência das águas percoladas do lixão, mais especificamente no Ponto 3. Porém, tal influência, não chega a atingir as águas do Rio Passa Três.

Todos os metais analisados apresentaram concentrações relativamente baixas, como pode ser observado pela análise das tabelas 1 e 2, estando inferiores aos limites estabelecidos na Resolução CONAMA (2005) para rios de Classe 2.

O ferro e o manganês apresentaram comportamento semelhante, tendo suas concentrações aumentadas significativamente pela ação do escorrimento superficial. $O$ Ponto 3 apresenta as maiores concentrações desses metais. Este aspecto pode ser explicado pelo fato destes elementos serem transportados em ambiente oxidante, sobretudo sobre a forma particulada, transporte típico de fluxos superficiais aerados.

O cádmio apresentou valores abaixo do limite de detecção nos pontos P1, P3, P4 e P5. O ponto P2 enquadrase dentro da classe 3 com relação a este metal, considerado tóxico. De acordo com a Organização Mundial de Saúde, a concentração limite para águas potáveis é de 0,005 mg/L. No ponto 2 encontra-se grande quantidade de lixo proveniente do lixão, podendo ser esta a origem de tal elemento químico, a despeito da presença de uma anomalia geoquímica de cádmio em sedimentos de corrente daquela região (LICHT, 2000).
O zinco só foi detectado no ponto 2 e nos pontos 4 e 5 no Rio Passa Três, em coleta realizada em estação seca, devido ao efeito da concentração. Apresentou um comportamento semelhante ao cádmio nas drenagens que circundam o lixão (pontos 1, 2 e 3), sendo que a origem dos dois metais no ponto 2 pode ser a mesma, ou seja, o grande volume de resíduos (metais, plásticos, entre outros) provenientes do lixão. Seu comportamento nos pontos 4 e 5 sugere a existência de outras fontes de poluição na bacia além do lixão, provavelmente o uso de fertilizantes na agricultura, pois as águas do ponto 4 , que apresentaram os teores mais elevados do metal $(0,06 \mathrm{mg} / \mathrm{L})$, não se encontram sobre a influência do depósito de lixo. Nas rochas da região não há uma relação direta do zinco com o cádmio (LICHT, 2000), o que afasta a hipótese de um controle geológico para a presença deste metal no ambiente local.

De acordo com a resolução CONAMA (2005), todos os valores de zinco encontram-se abaixo do valor máximo permitido para as águas das Classes 2 e 3 que é de $0,1 \mathrm{mg} / \mathrm{L}$.

De modo geral, o comportamento do alumínio foi semelhante em todos os pontos analisados, com uma maior concentração na estação seca, sendo que somente no ponto 3 observou-se o contrário. Valores acima de $1 \mathrm{mg} / \mathrm{L}$, de acordo com a resolução CONAMA (2005) são considerados elevados, sendo tais valores somente encontrados em águas ácidas, o que pode ser observado nos pontos 1 e 2 correspondentes a drenagens próximas ao lixão.

Com o objetivo de caracterizar quimicamente as águas da área de estudo, os valores encontrados para os cátions cálcio, magnésio, sódio e potássio e para os ânions carbonato, bicarbonato, cloreto e nitrato foram locados em um diagrama de Piper (Figura 11), o que permitiu verificar o comportamento conjunto dos íons majoritários, bem como a classificação das águas, como pode ser observado na Tabela 3.

Na Figura 11, os teores das espécies dissolvidas estão expressos em \% de equivalentes/L e caracterizam águas, em sua maioria, bicarbonatadas cálcicas e bicarbonatadas 
sódicas. Especificamente nos pontos localizados no Rio Passa Três (P4 e P5), as águas são bicarbonatadas cálcicas. A classificação cloretada sódica das águas do Ponto 3, drenagem próxima ao Lixão, chama a atenção e pode ser indicativa de poluição antropogênica oriunda das águas de percolação do lixão, pelos altos teores de cloro e sódio presentes.
A Figura 12 mostra o aumento de coliformes totais nas águas superficiais próximas ao lixão em período chuvoso, fato comum após precipitações fortes e curtas, devido o arraste de material contaminado pelas águas das chuvas. Nessas condições, o Ponto 3 passa a apresentar valores acima do máximo permitido para a Classe 3 de acordo com a Resolução CONAMA (1986), para coliformes totais.

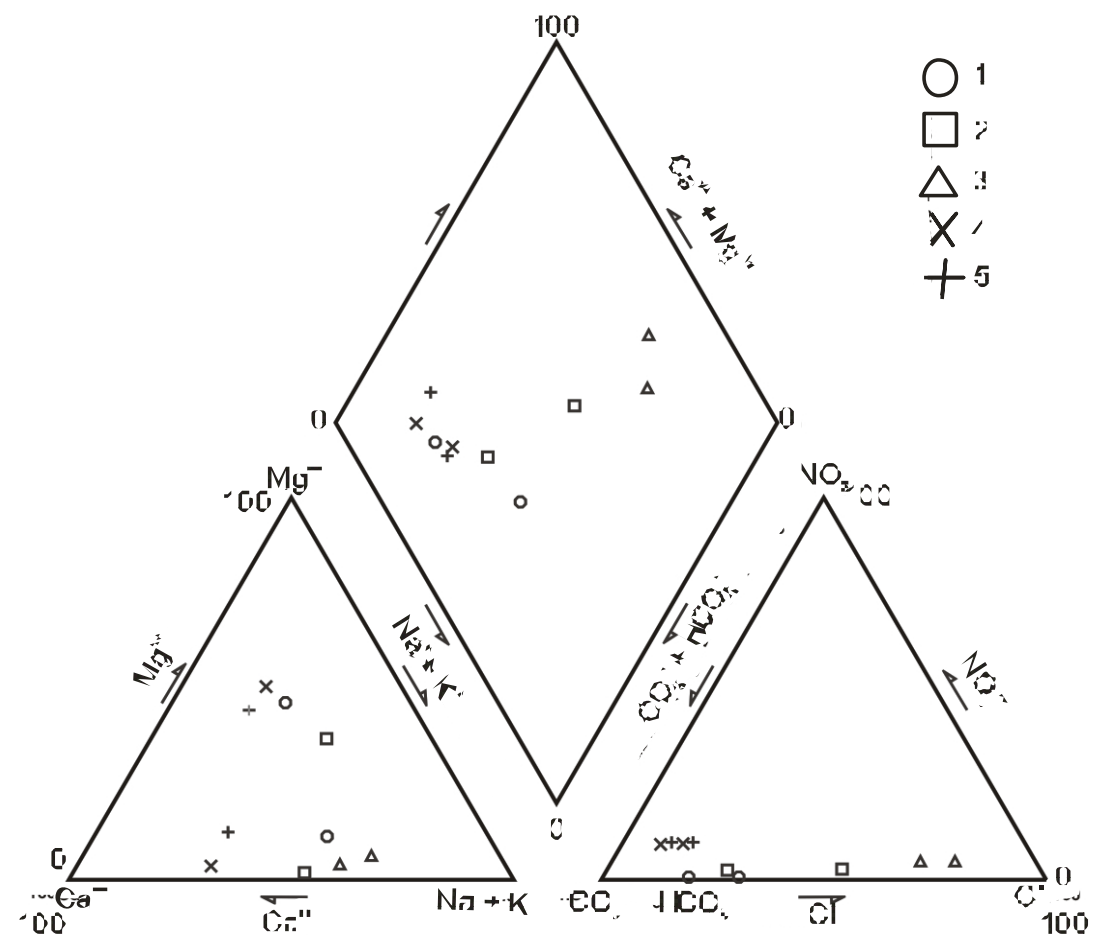

Figura 11 - Diagrama de Piper de amostras de água da área do Lixão de Palmas e seu entorno. Os dados são apresentados em \%Eq/L.

Tabela 3 - Classificação Hidroquímica das águas superficiais da área do lixão de Palmas - PR.

\begin{tabular}{|l|l|l|}
\hline Pontos amostrados & \multicolumn{1}{|c|}{ Estação Seca } & \multicolumn{1}{c|}{ Estação Chuvosa } \\
\hline Ponto 1 & Bicarbonatada-sódica & Bicarbonatada-cálcio-magnesiana \\
\hline Ponto 2 & Bicarbonatada-sódica & Bicarbonatada-sódica \\
\hline Ponto 3 & Cloretada-sódica & Cloretada-sódica \\
\hline Ponto 4 & Bicarbonatada-cálcio-magnesiana & Bicarbonatada-cálcio-magnesiana \\
\hline Ponto 5 & Bicarbonatada-cálcio-magnesiana & Bicarbonatada-cálcio-magnesiana \\
\hline
\end{tabular}

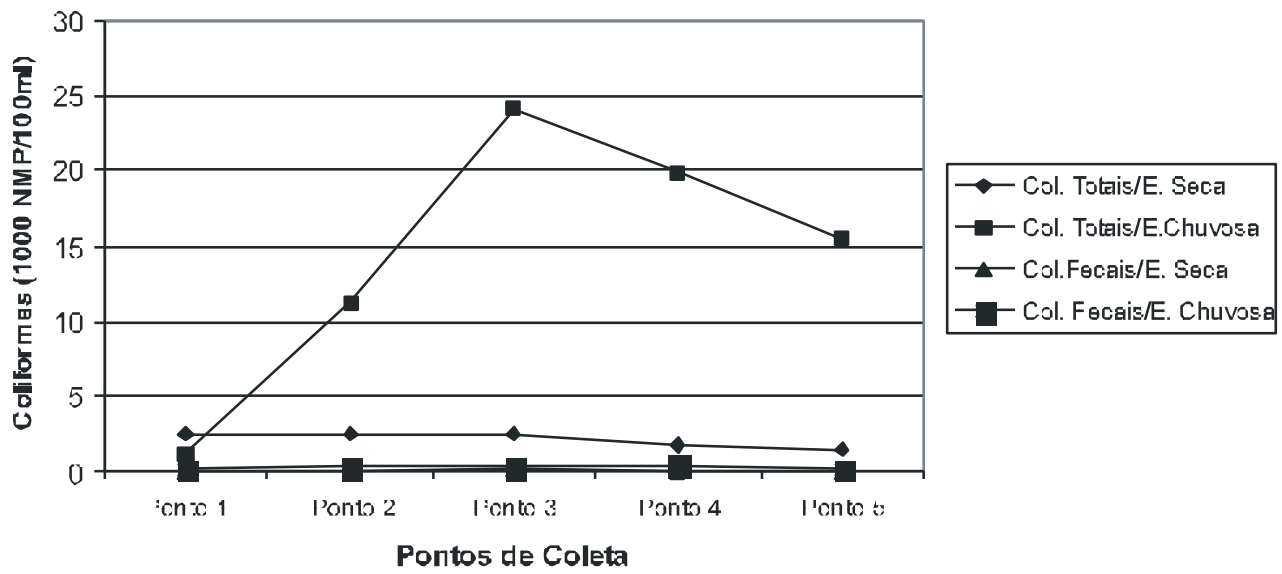

Figura 12 - Valores de Coliformes Totais e Coliformes Fecais encontrados nas águas superficiais da área do lixão de Palmas - PR. 


\section{Conclusões}

As seções de resistividade levantadas nos ensaios de caminhamento elétrico evidenciam uma zona condutora cuja resistividade pode chegar a 6 ?.m. Tal anomalia tem origem provável na presença de soluções provenientes do lixão. A composição química da água superficial na drenagem localizada nas proximidades do lixão, mostrou alterações na qualidade com relação às variáveis condutividade, sólidos totais, DBO, DQO, cloretos, sódio e potássio além de coliformes totais, o que vem confirmar a modelagem descrita para este ponto.

Os desvios significativos do padrão normal das medidas geofísicas, que são as anomalias, do ponto de vista ambiental, freqüentemente têm sido associados à presença de contaminantes. Assim, pontos de baixa resistividade podem servir como base para locação de piezômetros e poços de monitoramento visando um levantamento conclusivo sobre a qualidade da água subterrânea.

A despeito de não terem sido procedidas análises de águas subterrâneas no local, a comparação das composições de águas superficiais obtidas em locais com situações diferentes frente ao depósito de lixo, além dos levantamentos geofísicos, permitiu as conclusões apresentadas.

O monitoramento das águas superficiais foi realizado em duas drenagens situadas nas proximidades do lixão e em dois pontos do Rio Passa Três, um a montante e a outro a jusante do ponto de descarga das drenagens. Em muitas das variáveis analisadas, percebe-se um incremento dos valores na drenagem localizada a leste do depósito de lixo (Ponto 3), de modo especial na amostragem realizada em estação chuvosa, comprovando a influência do escoamento superficial para a contaminação das águas superficiais. A topografia local faz com que grande parte das águas que escorrem sobre o lixão acabem sendo conduzidas para a referida drenagem aumentando assim a concentração de contaminantes no Ponto 3.

A análise dos resultados mostra que a concentração dos contaminantes não exerce influência significativa sobre as águas do rio Passa Três, ficando mais restrita a micro-bacia que circunda o lixão.

Agradecimentos: A Prefeitura Municipal de Palmas, por toda a infra-estrutura disponibilizada para a concretização deste trabalho.

\section{Referências bibliográficas}

APHA-AMERICAN PUBLIC HEALTH ASSOCIATION; AMERICAN WATER WORKS ASSOCIATION, WATER ENVIRONMENTAL FEDERATION. 1998. Standard methods for examination of water. 20. ed. Baltimore.

BITTENCOURT A.V.L. 1982. Transporte de sólidos na bacia hidrográfica do rio Ivaí. Boletim Paran. de Geociências, 35, 354

BRASIL. Portaria n. 36, de 19 de janeiro de 1990. Estabelece procedimentos e responsabilidades relativos ao controle e a vigilância da qualidade de água para o consumo humano e seu padrão de potabilidade e dá outras providências. Diário Oficial da República Federativa do Brasil, Brasília, 10 jan.2001.

CONSELHO NACIONAL DO MEIO AMBIENTE. Resolução n.3. de março de 2005.

EMBRAPA. 1999. Centro Nacional de Pesquisa de Solos (Rio de Janeiro, RJ). Sistema Brasileiro de Classificação de Solos. Brasília, $412 \mathrm{p}$.

EMBRAPA. 1984. Serviço Nacional de Levantamento e Conservação de Solos (Rio de Janeiro, RJ). Levantamento de reconhecimento dos solos do Estado do Paraná. Londrina, (Embrapa - SNLCS. Boletim de Pesquisa,27; IAPAR. Boletim Técnico, 16).

GIBBS R.J. 1972. Water Chemistry of the Amazon River. Geoq. Cosmoq. Acta, 36, 1061-1066.

HYOUNG-SOO K, YEONGHWA K. 1997. Geoelectrical Monitoring in Nanji Waste Landfill. In: Congr. Inter. Soc. Bras. Geofis., São Paulo, Anais, 1, 494-498.

INSTITUTO AGRONÔMICO DO PARANÁ. 2003. Área de Ecofisiologia. Dados metereológicos. [mensagem de trabalho]. Mensagem recebida por: aamiapar@pr.gov.br em: 28 abr.2003.

INSTITUTO DE PESQUISAS TECNOLÓGICAS DO ESTADO DE SÃO PAULO. 2000. Lixo Municipal: Manual de Gerenciamento Integrado. São Paulo: IPT/CEMPRE.370p.
KRÜGER N. 2002. Palmas: paisagem e memória. Palmas: Fundação Santos Lima, 220p.

LICHT O.B.A 2000. geoquímica multielementar na gestão ambiental: Identificação e caracterização de províncias geoquímicas naturais, alterações antrópicas da paisagem, áreas favoráveis à prospecção mineral e regiões de risco para a saúde no Estado do Paraná, Brasil. Curitiba. Tese (Doutorado). Universidade Federal do Paraná

LOKE M.H. 1999. Electrical imaging surveys for environmental and engineering studies: A practical guide to $2 \mathrm{D}$ and $3 \mathrm{D}$ surveys. Malaysia.

MAACK R. 2002. Geografia física do estado do Paraná. 3. ed. Curitiba: Imprensa Oficial, $440 \mathrm{p}$.

McGAUHEY P.H. 1968. Engeneering management of water quality. New York: McGraw-Hill, 295 p.

NARDY A.J.R. 1995. Geologia e petrologia do vulcanismo Mesozóico da região central da Bacia do Paraná. Rio Claro, 316 f. Tese de Doutoramento - Instituto de Geociências e Ciências Exatas, UNESP.

PARISOT E.H., GUIGUER JR. N., REBOUÇAS A.C., CABRAL JR. D., DUARTE U. 1985. Monitoramento das Águas Subterrâneas Adjacentes ao Aterro Sanitário de Taubaté (SP) - Primeiros Resultados. Boletim IG-USP, Série Científica. 16. 32 - 45.

PROGRAMA DAS NAÇÕES UNIDAS PARA O MEIO AMBIENTE. 2002 Geo Brasil 2002: Perspectivas do Meio Ambiente no Brasil. Brasília. Convênio: PNUMA, Ministério do Meio AmbienteIBAMA. 447p.

RIGOTI A., PINHEIRO JR V, GOIS J.R. 1997. Mapeamento geoelétrico do Aterro da Lamenha Pequena (Curitiba-PR). In: 5th International Congress of Brazilian Geophysical Society. São José dos Campos: SBGf, 2, 1216-1219.

SANTOS C.B., BERALDO V.J., LADEIRA S.E.B., LEAL L.R.B., MELLO J.C. 2003. Caracterização do impacto ambiental sobre as águas subterrâneas causado pela disposição inadequada dos 
resíduos sólidos na cidade de Feira de Santana - Bahia. In: CONGRESSO BRASILEIRO DE GEOQUÍMICA, 9., Recife. Anais do IX Congresso Brasileiro de Geoquímica. Belém, 14-16.

VELOSO H.P., RANGEL FILHO A.L., LIMA J.C.A. 1991. Classificação da vegetação brasileira, adaptada a um sistema universal. IBGE, Rio de Janeiro, $123 \mathrm{p}$. 